\title{
A hybrid model to simulate the annual runoff of the Kaidu River in northwest China
}

\author{
Jianhua $\mathrm{Xu}^{1}$, Yaning Chen ${ }^{2}$, Ling Bai ${ }^{1}$, and Yiwen $\mathrm{Xu}^{1}$ \\ ${ }^{1}$ The Research Center for East-West Cooperation in China, School of Geographic Sciences, East China Normal University, \\ Shanghai, 200241, China \\ ${ }^{2}$ State Key Laboratory of Desert and Oasis Ecology, Xinjiang Institute of Ecology and Geography, Chinese Academy of \\ Sciences, Urumqi, 830011, China
}

Correspondence to: Jianhua Xu (jhxu@geo.ecnu.edu.cn)

Received: 9 December 2015 - Published in Hydrol. Earth Syst. Sci. Discuss.: 18 January 2016

Revised: 27 March 2016 - Accepted: 6 April 2016 - Published: 18 April 2016

\begin{abstract}
Fluctuant and complicated hydrological processes can result in the uncertainty of runoff forecasting. Thus, it is necessary to apply the multi-method integrated modeling approaches to simulate runoff. Integrating the ensemble empirical mode decomposition (EEMD), the back-propagation artificial neural network (BPANN) and the nonlinear regression equation, we put forward a hybrid model to simulate the annual runoff (AR) of the Kaidu River in northwest China. We also validate the simulated effects by using the coefficient of determination $\left(R^{2}\right)$ and the Akaike information criterion (AIC) based on the observed data from 1960 to 2012 at the Dashankou hydrological station. The average absolute and relative errors show the high simulation accuracy of the hybrid model. $R^{2}$ and AIC both illustrate that the hybrid model has a much better performance than the single BPANN. The hybrid model and integrated approach elicited by this study can be applied to simulate the annual runoff of similar rivers in northwest China.
\end{abstract}

\section{Introduction}

The description of hydrological processes is the basis of hydrological modeling and simulation. Many models have been developed for describing hydrological processes over the past decades. From different perspectives, these hydrologic models can be classified as stochastic and deterministic models according to their mathematical property, classified as conceptual and physically based models according to the physical processes involved in modeling, or classified as lump and distributed models according to the spatial description of the watershed process (Refsgaard, 1996; Moglen and Beighley, 2002).

Among the hydrologic models, distributed hydrological models are widely used. The Soil, Water, Atmosphere and Plant (SWAP) model has been intensively validated during the past 2 decades (van Dam et al., 1997; Gusev and Nasonova, 2003; Kroes et al., 2000; Gusev et al., 2011; Ma et al., 2011). Different versions of SWAP are validated against various observed hydrothermal characteristics. The validations are performed both for "point" experimental sites and for catchments and river basins with different areas (from $10^{-1}$ to $10^{5} \mathrm{~km}^{2}$ ) on a long-term basis and under different environmental conditions (Nasonova and Gusev, 2007). The Soil and Water Assessment Tool (SWAT) model is a continuation of almost 30 years of modeling efforts conducted by the USDA Agricultural Research Service and is widely used around the world. A number of scientists have used SWAT model for simulating streamflow and related hydrologic analyses (Gan and Luo, 2013; Levesque et al., 2008; Liu et al., 2008, 2014; Luo et al., 2012; Shope et al., 2014; Lin et al., 2015; Yang and Musiake, 2003). According to the investigation by Gassman et al. (2007), there have been hundreds of published articles including SWAT applications, reviews of SWAT components, or other studies of SWAT in the past decades.

However, the application prerequisite of the distributed hydrological model is to successfully obtain a large number of parameters (such as temperature, precipitation, evapotranspiration, topography, land use, soil moisture, and vegetation 
coverage) at each grid cell (Yang et al., 2015). But for a large river basin with sparse meteorological and hydrological sites as well as lacking of observed data, it is difficult to obtain the large number of parameters mentioned above at each grid cell. Therefore, more studies are required to explore the hydrological processes from different perspectives by means of different methods.

In fact, hydrologists have used many methods for understanding the variation pattern of streamflow in the last 2 decades. Various methods such as the grey model (Yu et al., 2001; Trivedi and Singh, 2005), functional-coefficient time series model (Shao et al., 2009), wavelet analysis (Labat et al., 2000a, b; Lane, 2007; Sang, 2012), genetic algorithm (Seibert, 2000), and artificial neural network (Hsu et al., 1995; Hu et al., 2008; Tokar and Johnson, 1999; Modarres, 2009) have been widely used for hydrologic analysis and streamflow simulation. Hybrid models have been paid special attention (Nourani et al., 2009; Zhao et al., 2009; Sahay and Srivastava, 2014; Xu et al., 2014; Yarar, 2014).

The water resource in northwest China which can be utilized is mainly from the streamflow of inland rivers. Hence the runoff variation of inland rivers has aroused more and more attention (Chen et al., 2009; Li et al., 2008; Wang et al., 2010; Xu et al., 2011). However, the runoff variation pattern of inland rivers in northwest China has not been clearly comprehended because of the complexity of the hydrological process (Xu et al., 2009, 2010). To understand the runoff variation pattern of inland rivers in northwest China, this study selected the Kaidu River as a typical case of an inland river in northwest China and integrated the ensemble empirical mode decomposition (EEMD), the back-propagation artificial neural network (BPANN) and nonlinear regression equation to conduct a hybrid model for simulating annual runoff (AR).

\section{Study basins and data}

\subsection{Study area}

The Kaidu River is situated at the north fringe of Yanqi Basin on the south slope of the Tianshan Mountains in Xinjiang and is enclosed within latitudes $42^{\circ} 14^{\prime}-43^{\circ} 21^{\prime} \mathrm{N}$ and longitudes $82^{\circ} 58^{\prime}-86^{\circ} 05^{\prime} \mathrm{E}$ (Fig. 1). The river starts from the Hargat Valley and the Jacsta Valley in Sarming Mountain with a maximum altitude of $5000 \mathrm{~m}$ (the middle part of the Tianshan Mountain) and ends in Bosten Lake, which is located in the Bohu County of Xinjiang. This lake is the largest lake in Xinjiang (also once the largest interior fresh water lake in China) and immediately starts another river known as the Kongque River. The catchment area of the Kaidu River above Dashankou is $18827 \mathrm{~km}^{2}$, with an average elevation of $3100 \mathrm{~m}$ (Chen et al., 2013).

Bayinbuluke wetland, which is in the Kaidu River basin, is the largest wetland of the Tianshan Mountain area. The large areas of grassland and marshes in Bayinbuluke wetland

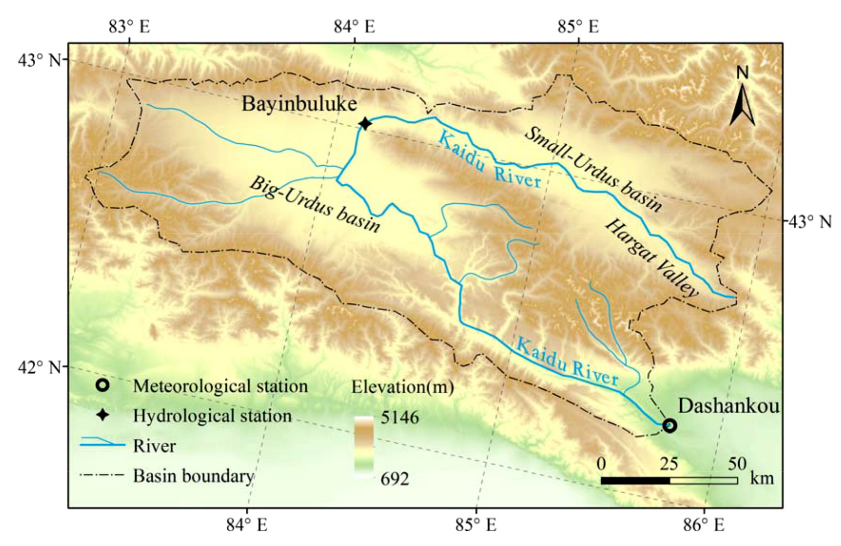

Figure 1. Location of the Kaidu River, northwest China.

have provided favorable conditions for swan survival and reproduction. For this reason, it has become the China's sole state-level swan nature reserve. The annual average temperature is only $-4.6^{\circ} \mathrm{C}$, and the extreme minimum temperature is $-48.1^{\circ} \mathrm{C}$. The snow cover days are as many as 139.3 days, and the largest average snow depth is $12 \mathrm{~cm}$. As a unique high alpine cold climate with unique topography, it cultivates various alpine grassland and meadow ecosystems, having abundant aquatic plants and animals and good grassland resources. It is the birthplace and water-saving place of the Kaidu River and plays a crucial role in regulating and preserving water and maintaining water balance. It also plays an utmost important role in protecting the Bosten Lake, its surrounding wetlands, and the ecological environment and green corridor of the lower reaches of the Tarim River.

\subsection{Data}

The purpose of this study is to well understand the internal variation pattern by simulation method, so we used the AR time series data from 1960 to 2012, which were observed at the Dashankou hydrological station. To analyze the correlation between the AR and regional climate change, the data of precipitation and temperature in the same period at the Bayinbuluke meteorological station were used. The two stations are located in the mountainous area (the source area of the river) where human activities are relatively rare. Therefore, it was assumed that the observed data reflect natural conditions (Chen et al., 2013). In order to compare the hydrological cycle of the Kaidu River and the El Niño meteorological phenomena, we also used the NINO3.4 index from NOAA Earth System Research Laboratory (http: //www.esrl.noaa.gov/psd/data/climateindices/list/\#Nina34).

\section{Methods}

To simulate the AR, we made a hybrid model by integrating EEMD, BPANN and regression equation. We firstly used 
the EEMD method to decompose the AR into four intrinsic mode functions (i.e., IMF1, IMF2, IMF3 and IMF4) and a trend (RES). Then we simulated IMFs by the BPANN, and simulated RES (trend) by a nonlinear regression equation. Finally, the simulated values for AR are obtained from the summation of the simulated results of the trend (RES) and IMFs. The framework of the hybrid model is shown in Fig. 2.

\subsection{EEMD method}

The EEMD is a new noise-assisted data analysis method based on the empirical mode decomposition (EMD), which defines the true IMF components as the mean of an ensemble of trials, each consisting of a signal plus white noise of finite amplitude (Wu and Huang, 2004, 2009).

The EMD has been developed for nonlinear and nonstationary signal analysis, though only empirically. The EMD decomposes a signal into several IMFs; then the frequencies of the IMFs are arranged in decreasing order (high to low), where the lowest frequency of the IMF components represents the overall trend of the original signal or the average of the time series data (Huang et al., 1998, 1999). Most importantly, each of these IMFs must satisfy two conditions: (1) the number of extrema and the number of zero crossings must be equal or differ at most by one; (2) at any point, the mean value of the envelope defined by the local maxima and local minima must be zero.

The EMD processing is as follows.

For the original signal $x(t)$, first we find all the local maxima and minima, and then use the cubic spline interpolation method to form the upper envelope $u_{1}(t)$ and the lower envelope $u_{2}(t)$; the local mean envelope $m_{1}(t)$ can be expressed as

$m_{1}(t)=\frac{1}{2}\left(u_{1}(t)+u_{2}(t)\right)$.

The first component $h_{1}(t)$ can be obtained by subtracting the local mean envelope $m_{1}(t)$ from the original signal $x(t)$, with the mathematical expression as follows:

$h_{1}(t)=x(t)-m_{1}(t)$.

If $h_{1}(t)$ does not satisfy the IMF conditions, regard it as the new $x(t)$, and repeat the steps in Eqs. (1) and (2) $k$ times until $h_{1 k}(t)$ is obtained as an IMF.

$h_{1 k}(t)=h_{1(k-1)}(t)-m_{1 k}(t)$

Designate $C_{1}=h_{1 k}$, and select a stoppage criterion defined as follows:

$\mathrm{SD}=\sum_{t=0}^{T}\left[\frac{\left(h_{1(k-1)}(t)-h_{1 k}(t)\right)}{h_{1(k-1)}(t)}\right]^{2}$

Here, the standard deviation (SD) is smaller than a predetermined value. If the above process is repeated too many

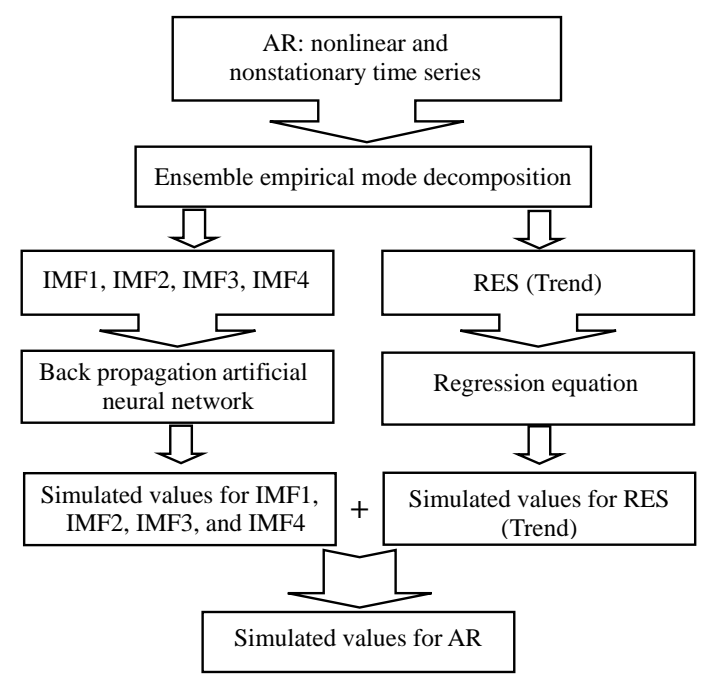

Figure 2. The framework of the hybrid model to simulate AR.

times, the IMF will become a pure frequency modulation signal with constant amplitude in the actual operation, possibly resulting in loss of its actual meaning.

Once the first IMF component is determined, the residue $r_{1}(t)$ can also be obtained by separating $C_{1}$ from the rest of the data, i.e.,

$r_{1}(t)=x(t)-C_{1}$

By taking the residue $r_{1}(t)$ as new data and repeating steps (Eqs. 1-5), a series of IMFs - namely, $C_{2}, C_{3}, \ldots, C_{n}-$ can be obtained.

The sifting process finally stops when the residue, $r_{n}(t)$, becomes a monotonic function or a function with only one extremum from which no more IMFs can be extracted. Finally, the original signal $x(t)$ can be reconstructed by $n$ IMFs (i.e., $\left.C_{i}(t)\right)$ and a residue $r_{n}(t)$ as follows:

$x(t)=\sum_{i=1}^{n} C_{i}(t)+r_{n}(t)$.

Although EMD has many merits, there is a shortcoming of mode mixing in EMD. To overcome the mode mixing problem, the EEMD has been developed for nonlinear and nonstationary signal analysis (Wu and Huang, 2009).

The principle of EEMD is that adding white noise to the data, which distributes uniformly in the whole timefrequency space, the bits of signals of different scales can be automatically designed onto proper scales of reference established by the white noise.

The EEMD algorithm is straightforward and can be described as follows: first, add a white noise series to the original signal

$x_{i}(t)=x(t)+n_{i}(t)$ 


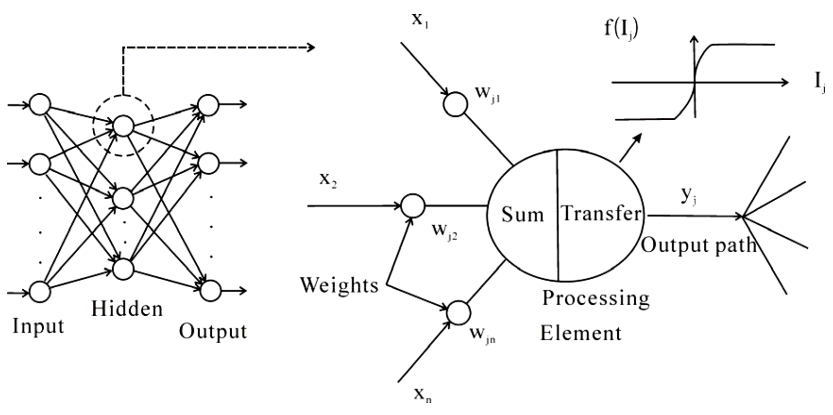

Figure 3. The back-propagation artificial neural network.

where $x_{i}(t)$ is the new signal after adding $i$ th white noise to the original signal data $x(t) ; n_{i}(t)$ is the white noise. Then, decompose the signal with added white noise into IMFs using EMD according to the steps of Eqs. (1)-(5); the corresponding IMF components $C_{i j}(t)$ and residue component $r_{i}(t)$ of the decompositions were obtained. Finally, adopt the means of the ensemble corresponding to the IMFs of the decompositions as the final result, namely

$C_{j}(t)=\frac{1}{N} \sum_{i=1}^{N} C_{i j}(t)$,

where $C_{j}(t)$ is the final $j$ th IMF component, $N$ is the number of white noise series, and $C_{i j}(t)$ denotes the $j$ th IMF from the added white noise trial.

Wu and Huang (2009) noted that the amplitude size of the added noise exerts little influence on the decomposition results on the condition that it is limited, is not vanishingly small or very large, and can include all possibilities. Therefore, the application of the EEMD method does not rely on subjective involvement; it is an adaptive data analysis method.

The significance test in EEMD can be carried out by means of white noise ensemble disturbance, to get each IMF credibility (Wu and Huang, 2009; Huang and Shen, 2005).

In addition, to solve the overshooting and undershooting phenomenon of the impact of the boundary on the decomposition process, mirror-symmetric extension (Huang and Shen, 2005; Xue et al., 2013) was used to address the EEMD decomposition boundary problem.

The residue of EEMD is a monotonic function that intrinsically presents the overall trend of a time series (Wu et al., $2007,2009,2011)$. Thus, the reconstruction of signal $x(t)$ based on EEMD can be obtained as follows:

$x(t)=\mathrm{IMF} 1+\mathrm{IMF} 2+\ldots+\mathrm{IMF}_{n}+\mathrm{RES}($ trend $)$,

where RES is the residue of EEMD, i.e., the trend of signal $x(t)$.

In this study, we decomposed the AR time series to a trend (RES) and four IMFs.

The MATLAB programs for EEMD are provided by RCADA, National Central University, which can be down-

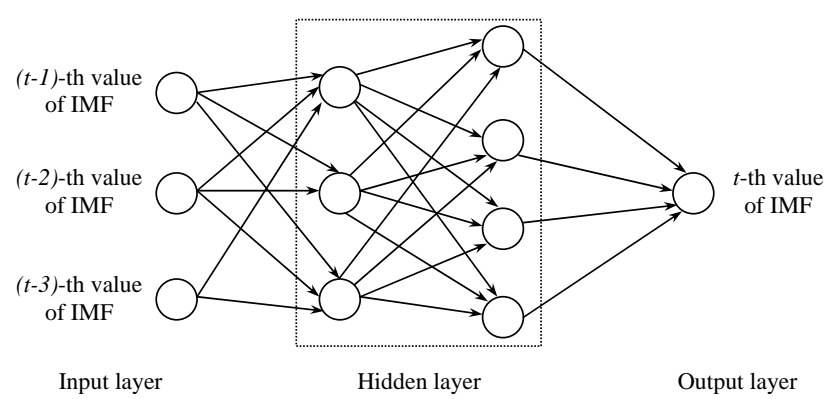

Figure 4. Four-tier structure BPANN to simulate the IMFs of AR.

loaded at the website (http://rcada.ncu.edu.tw/research1_ clip_ex.htm).

\subsection{BPANN}

In the BPANN, a number of smaller processing elements (PEs) are arranged in layers: an input layer, one or more hidden layers, and an output layer (Hsu et al., 1995). The input from each PE in the previous layer $\left(x_{i}\right)$ is multiplied by a connection weight $\left(w_{j i}\right)$. These connection weights are adjustable and may be likened to the coefficients in statistical models. At each PE, the weighted input signals are summed and a threshold value $\left(\theta_{j}\right)$ is added. This combined input $\left(I_{j}\right)$ is then passed through a transfer function $(f(\cdot))$ to produce the output of the PE $\left(y_{j}\right)$. The output of one PE provides the input to the PEs in the next layer. This process is summarized (Maier and Dandy, 1998) in Eqs. (13) and (14) and illustrated in Fig. 3.

$I_{j}=\sum w_{j i} x_{i}+\theta_{j}$

$y_{i}=f\left(I_{j}\right)$

The error function of network at the $t$ th moment is defined as follows:

$E(t)=\frac{1}{2} \sum_{j=1}^{q}\left[y_{j}(t)-d_{j}(t)\right]^{2}$,

where $y_{i}(t)$ is the actual output and $d_{i}(t)$ is the desired output, respectively corresponding to $i$ th neuron at $t$ th moment. When $E(t) \leq \varepsilon$ ( $\varepsilon$ is a given error in advance), the network will stop training, and the network model at this time is just what we need.

We used the BPANN with a four-tier structure to simulate IMF1, IMF2, IMF3 and IMF4 of the AR based on the results from the EEMD. The four-tier structure of the BPANN for each IMF is as follows (Fig. 4): an input layer with three variables, i.e., $(t-1)$ th, $(t-2)$ th and $(t-3)$ th value of the IMF; two hidden layers, in which the first layer contains three neurons and the second layer contains four neurons; and an output layer with a variable, i.e., $t$ th value of the IMF.

The transfer function from the input layer to two hidden layers is tansig, i.e., the hyperbolic tangent sigmoid 
transfer function (http://www.mathworks.com/help/nnet/ref/ tansig.html). The transfer function from the hidden layers to the output layer is purelin, i.e., the linear function (http: //www.mathworks.com/help/nnet/ref/purelin.html).

The purpose of our BPANN is to capture the relationship between a historical set of inputs and corresponding outputs. As mentioned above, this is achieved by repeatedly presenting examples of the input/output relationship to the model and adjusting the model coefficients (i.e., the connection weights) in an attempt to minimize an error function between the historical outputs and the outputs predicted by the model. This calibration process is generally referred to as "training". The aim of the training procedure is to adjust the connection weights until the global minimum in the error surface has been reached. The network training process (Moghadassi et al., 2009) is summarized in Fig. 5.

The back-propagation process is commenced by presenting the first example of the desired relationship to the network. The input signal flows through the network, producing an output signal, which is a function of the values of the connection weights, the transfer function and the network geometry. The output signal produced is then compared with the desired (historical) output signal with the aid of an error (cost) function.

Because it can train any network as long as its weight, net input, and transfer functions have derivative functions (Kermani et al., 2005), we selected the Levenberg-Marquardt optimization, i.e., trainlm (http://www.mathworks.com/help/ nnet/ref/trainlm.html), as a network training function in the computing environment of MATLAB.

\subsection{Nonlinear regression}

In order to simulate the trend of AR, we fitted a quadratic polynomial by using the nonlinear regression based on the results from the EEMD. We conducted the quadratic polynomial regression equation as follows:

$y=a t^{2}+b t+c$,

where the independent variable $(t)$ is the time variable, and the dependent variable $(y)$ represents the trend of AR, which is the RES obtained from the EEMD. The coefficients ( $a, b$ and $c$ ) are obtained by the method of least squares (Lancaster and Šalkauskas, 1986).

\subsection{Simulated effect test}

In order to identify the uncertainty of the simulated results, the coefficient of determination was calculated as follows:

$$
R^{2}=1-\frac{\mathrm{RSS}}{\mathrm{TSS}}=1-\frac{\sum_{i=1}^{n}\left(y_{i}-\hat{y}_{i}\right)^{2}}{\sum_{i=1}^{n}\left(y_{i}-\bar{y}\right)^{2}}
$$

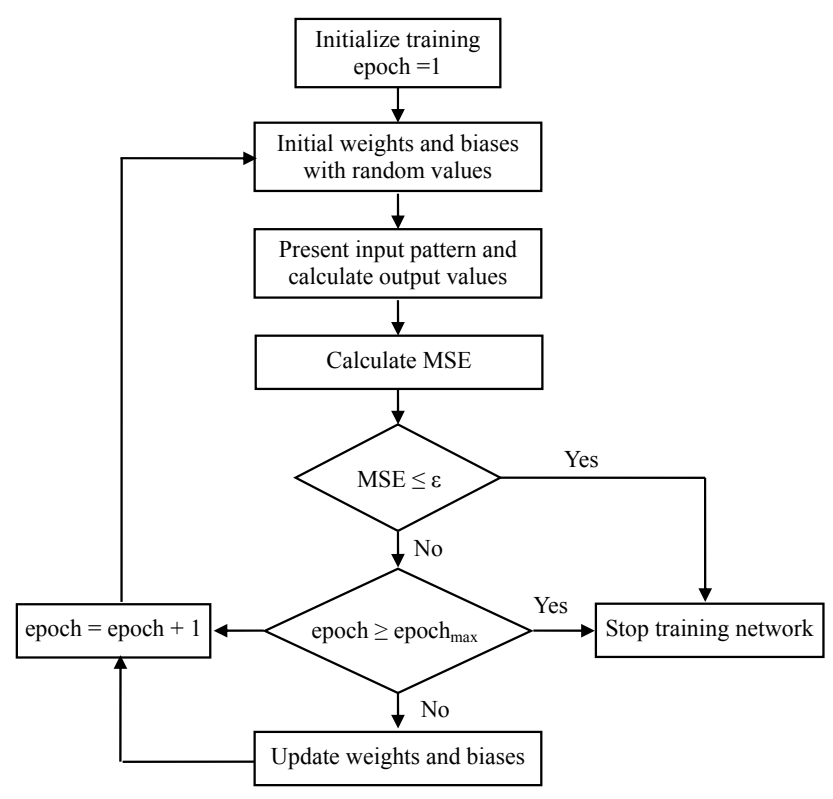

Figure 5. Back-propagation training process.

where $R^{2}$ is the coefficient of determination; $\hat{y}_{i}$ and $y_{i}$ are the simulated value and actual data of AR, respectively; $\bar{y}$ is the mean of $y_{i}(i=1,2, \ldots, n) ; \operatorname{RSS}=\sum_{i=1}^{n}\left(y_{i}-\hat{y}_{i}\right)^{2}$ is the residual sum of squares; and TSS $=\sum_{i=1}^{n}\left(y_{i}-\bar{y}\right)^{2}$ is the total sum of squares. The coefficient of determination is a measure of how well the simulated results represent the actual data. A bigger coefficient of determination indicates a higher certainty and lower uncertainty of the estimates (Xu, 2002).

To compare the goodness of fit between our hybrid model and single BPANN, we also used the measure of the Akaike information criterion (AIC) (Anderson et al., 2000). The formula of AIC is as follows:

$\mathrm{AIC}=2 k+n \ln (\mathrm{RSS} / n)$,

where $k$ is the number of parameters estimated in the model; $n$ is the number of samples; and RSS is the same as in Eq. (14). A smaller AIC indicates a better model (Burnham and Anderson, 2002).

\section{Results and discussion}

\subsection{Decomposition for AR}

Figure 6 reveals anomaly fluctuations of the AR time series in the Kaidu River during 1960-2012. It is clear that the AR shows a strong nonlinear and nonstationary variation. Because of the nonlinear and nonstationary characteristics, it is difficult to show the change law of the AR time series.

To discover intrinsic modes in the signal of AR, we decomposed the AR time series by the EEMD method. For de- 


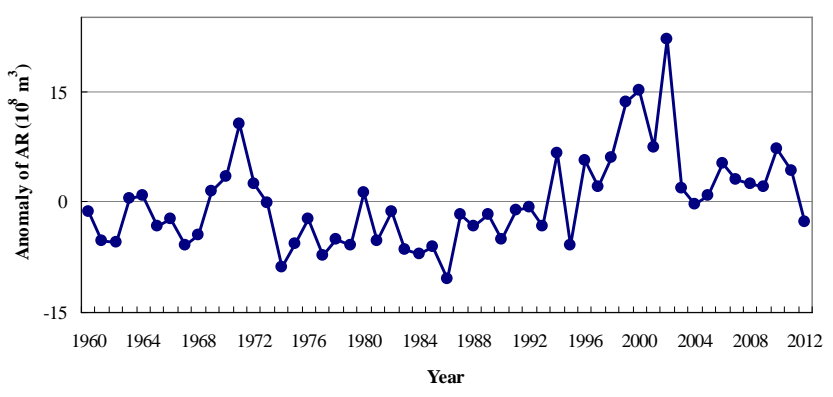

Figure 6. The anomaly time series of AR in the Kaidu River during 1960-2012.

composing the AR time series, the ensemble number is 100 , and the added noise has an amplitude that is 0.2 times the standard deviation of the corresponding data, and four IMF components (IMF1-4) and a trend component (RES) were obtained. The decomposed results are showed in Fig. 7.

The significance test showed that IMF2, IMF3 and IMF4 reaches above the $95 \%$ confidence level, while IMF1 reach above $90 \%$ confidence level. The variance contribution rate of IMF1, IMF2, IMF3, IMF4 and RES (trend) is 28.29, $19.61,10.11,8.58$ and $33.41 \%$, respectively. The summation of IMF1, IMF2, IMF3, IMF4 and RES represent the reconstruction for AR time series, which is very highly correlative with its original data series. It can be seen that the reconstruction for AR series with the original data series is almost exactly the same (Fig. 8). This result illustrates that the decomposition of the AR time series by EEMD had a good prospective effect.

Each IMF component in Fig. 7 has its own physical meaning, which reflects the inherent oscillation at a characteristic scale. The four IMF components (IMF1-4) reflect the fluctuation characteristics from high frequency to low frequency. IMF1 presents the highest-frequency fluctuation, and IMF4 shows the lowest-frequency fluctuation. The fluctuation frequency of IMF2 is higher than that of IMF3 but lower than that of IMF1, and the fluctuation frequency of IMF3 is higher than that of IMF4 but lower than that of IMF2. The residual (RES) of EEMD is a monotonic function that presents the overall trend of the AR time series.

The multi-scale oscillations of runoff in the Kaidu River reflect not only the periodic changes of the climatic system under external forcing but also the nonlinear feedback of the climatic system. To compare the hydrological cycle of the Kaidu River and the El Niño meteorological phenomena, we also decomposed the NINO3.4 index data series in the same period by using the EEMD method. The results show that the four IMF components (IMF1-4) of the NINO3.4 index data series respectively display quasi-3-year, quasi6-year, quasi-11-year and quasi-28-year periodic fluctuation (Fig. 9), whereas the four IMF components (IMF1-4) of the AR series in the Kaidu River respectively show quasi-3-year, quasi-6-year, quasi-11-year and quasi-27-year cyclic varia-
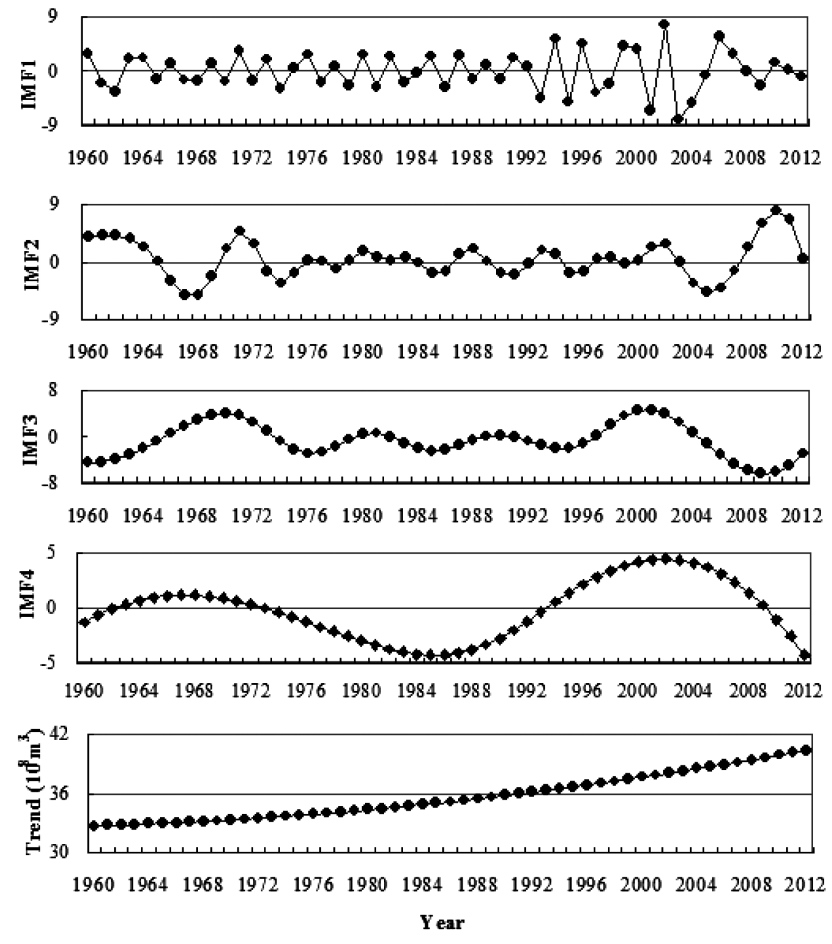

Figure 7. The EEMD results for the time series of AR in the Kaidu River.

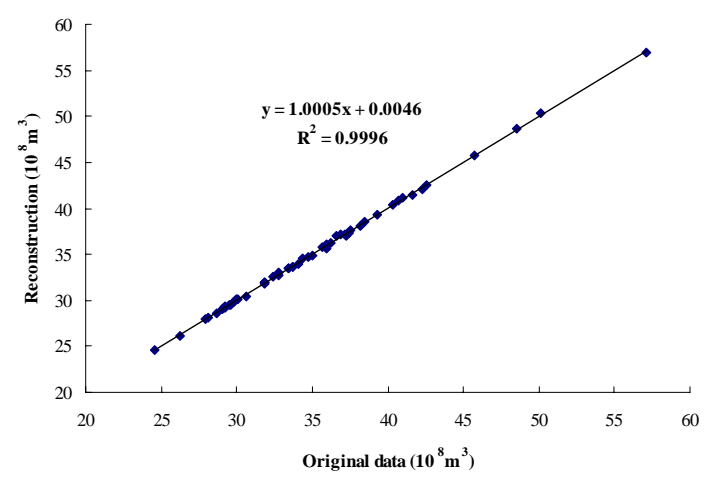

Figure 8. The correlation between the reconstruction of AR time series based on EEMD and its original data.

tion (Fig. 7). Although the two cycles are not completely the same, they show some comparability. A study showed that there was a possible variability in droughts and wet spells over China on the multi-year or decadal scale when one strong El Niño event happened, but it does not mean that each El Niño event must cause a wet-dry change (Su and Wang, 2007). Similarly, the larger fluctuations of runoff in the Kaidu River on the multi-year or decadal scale possibly relate to strong El Niño events, but it does not mean that a big change of runoff certainly corresponds to a strong El Niño event. The possible reason is that the influencing factors include not only an El Niño event but also other factors. 

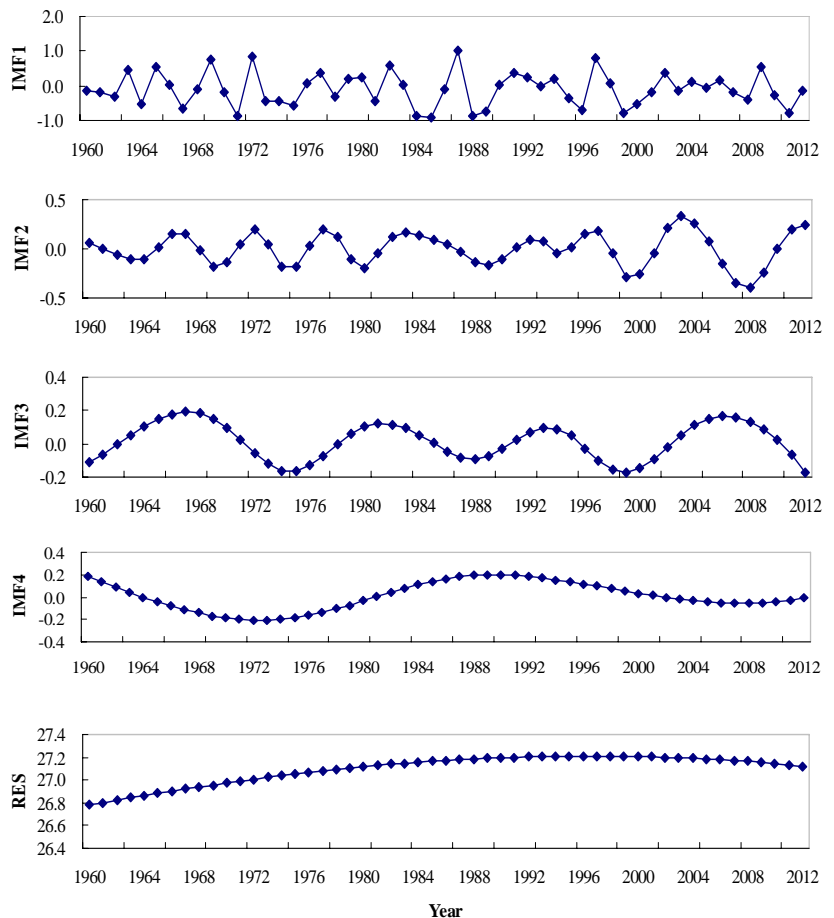

Figure 9. The EEMD results for the NINO3.4 index data series during 1960-2012.

In fact, there are many other factors affecting the runoff, such as the varied topography, vegetation cover and construction of a water conservancy project (Chen et al., 2013). Our previous study showed that the runoff process of the Kaidu River is closely related to the regional climate change $(\mathrm{Xu}$ et al., 2014; Bai et al., 2015). To compare the cycles between the runoff in the Kaidu River and the regional climatic factors in the study period, we used the EEMD method to decompose the data series of annual precipitation (AP) and annual average temperature (AAT) into four IMF components (IMF1-4) and a trend. The results are similar to that of the AR: the AP and AAT on the whole show an upward trend; meanwhile (a) the AP presents quasi-3-year, quasi-6-year, quasi-11-year and quasi-27-year cycles, and (b) the AAT displays quasi-3-year, quasi-6-year, quasi-13-year and quasi27-year cycles. To further analyze the correlation between runoff and precipitation and temperature, we reconstructed interannual and interdecadal precipitation and temperature variations, in which the interannual precipitation/temperature was obtained by IMF1 and IMF2, while the interdecadal precipitation/temperature was obtained by IMF3 and IMF4. The results of multi-scale correlation analysis among annual runoff, annual precipitation and annual average temperature are shown in Table 1. Evidently - although there are differences in the length and strength of the periods among the precipitation, temperature and runoff changes - the positive correlations between runoff, precipitation and temperature are still significant except for interannual precipitation vs. inter-
Table 1. Correlations between runoff and climate factors.

\begin{tabular}{lll}
\hline Timescale & $\begin{array}{l}\text { Precipitation } \\
\text { vs. runoff }\end{array}$ & $\begin{array}{l}\text { Temperature } \\
\text { vs. runoff }\end{array}$ \\
\hline Interannual scale & $0.666^{* *}$ & $0.416^{* *}$ \\
Interannual vs. interdecadal scale & 0.205 & $0.441^{* *}$ \\
Interdecadal vs. interannual scale & $0.279^{*}$ & $0.438^{* *}$ \\
Interdecadal scale & $0.822^{* *}$ & $0.617^{* *}$ \\
\hline Note: ${ }^{* *}$ correlation is significant at the 0.01 level (two-tailed); ${ }^{*}$ correlation is
\end{tabular}
significant at the 0.05 level (two-tailed)

Table 2. $R^{2}$ and AIC value of simulation models for the IMFs and trend of AR.

\begin{tabular}{lcr}
\hline IMFS & $R^{2}$ & AIC \\
\hline IMF1 & 0.9107 & 0.5789 \\
IMF2 & 0.9619 & -54.9342 \\
IMF3 & 0.9859 & -105.9041 \\
IMF4 & 0.9980 & -204.2977 \\
Trend & 0.9999 & -405.1425 \\
\hline
\end{tabular}

decadal runoff, suggesting that the precipitation and temperature are two main causes of runoff variation. Furthermore, the higher correlation between runoff and climate factors is precipitation, followed by temperature at both the interannual and interdecadal scales.

\subsection{Simulation for IMFs}

In order to capture the relationship between the historical data and real-time output, we constructed the BPANN with a four-tier structure to simulate IMF1, IMF2, IMF3 and IMF4 of the AR based on the results from the EEMD. Using MATLAB software (http://www.mathworks.com/products/ matlab/), we selected the transfer function for the input layer to the hidden layer and the hidden layer to the output layer as the tangent sigmoid function (tansig) and the linear function (purelin), respectively, and chose "trainlm" as a training function to train the network. We set the learning rate as 0.01 and the training error accuracy as 0.01 , and randomly extracted 70,15 , and $15 \%$ of the data in the time series of each IMF as the training, testing, and validation samples, respectively. We finally obtained the optimized network for each IMF after thousands of training processes. Using the optimized networks, we obtained the simulated results for IMF1, IMF2, IMF3 and IMF4 (Fig. 10).

Table 2 presents the $R^{2}$ and AIC value of the simulation model (the optimized networks) for each IMF. The big coefficient of determination $\left(R^{2}\right)$ indicates that the simulated accuracy for each IMF is very high. The smaller AIC value means the better simulation effect, which indicates that the simulated effect of IMF4 is the best, then followed by IMF3, IMF2, and IMF1. 

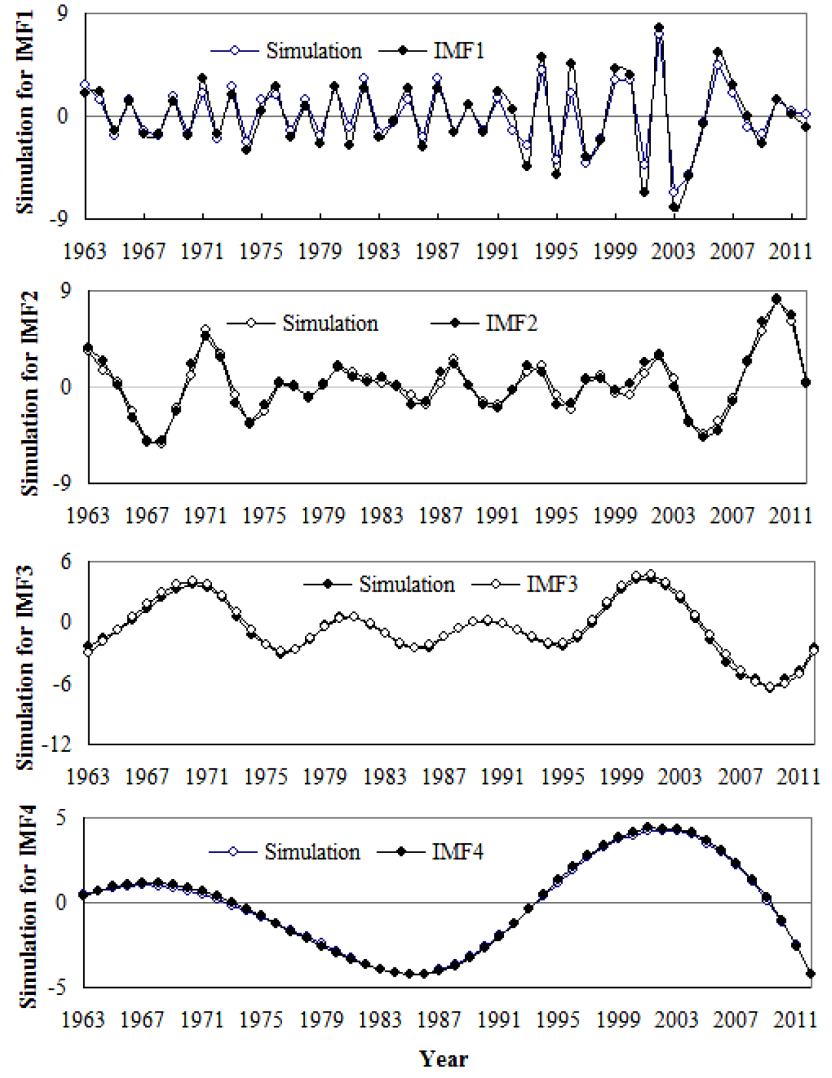

Figure 10. Simulation for the IMFS of AR by BPANN.

\subsection{Simulation for the trend}

As mentioned above, the residue (RES) of EEMD presents the overall trend of the AR time series. Because it is a monotonic function, we can simulate the trend by a regression equation. Based on the data of RES from EEMD, we obtained the regression equation by using the method of least squares as the following quadratic polynomial:

$y=0.002 t^{2}-7.7975 t+7632.6$,

where $t$ is the time, which is measured by year, and $y$ is the simulated value for the trend of the AR time series.

The coefficient of determination of Eq. (16) is as high as 0.9999. It is evident that the simulated effect of the RES (trend) is even better than that of IMF1, IMF2, IMF3 and IMF4 (also see Table 2). The simulated results for the trend of AR time series calculated by Eq. (16) are shown as Fig. 11.

\subsection{Simulation for AR}

Based on the idea and framework of the hybrid model mentioned previously in the Methods section of this study, we can calculate the simulated value of AR for each year by summing the simulated value of IMF1, IMF2, IMF3, IMF4 and RES. By summing the simulated value of IMF1, IMF2,

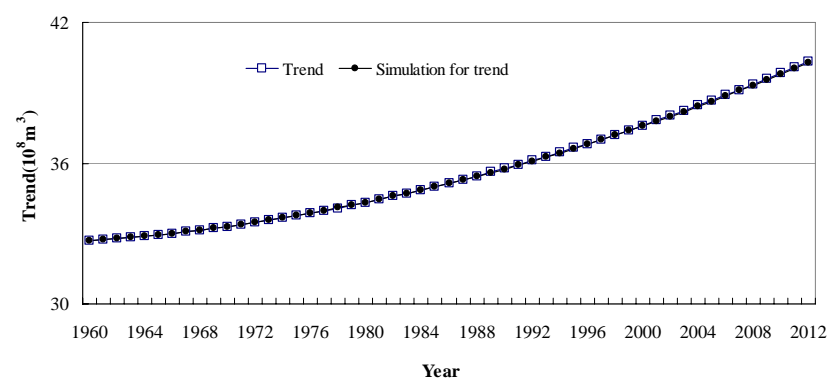

Figure 11. Simulation for the trend of AR by nonlinear regression equation.

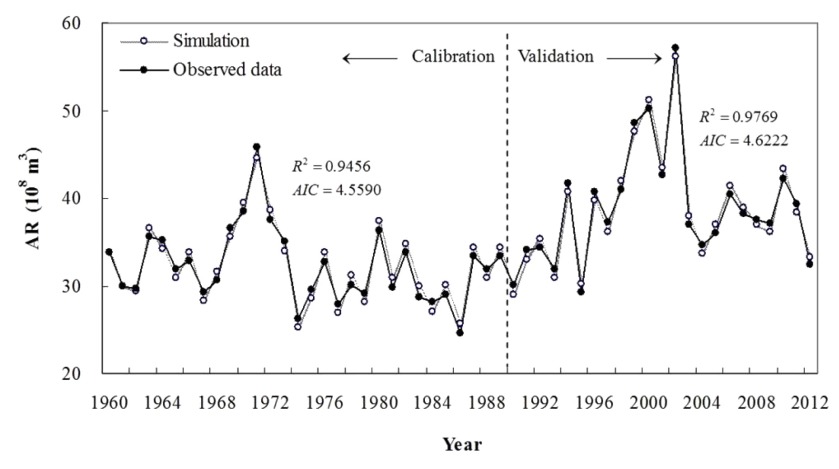

Figure 12. Comparisons between the observed data of AR and its simulated values for calibration period (1960-1989) and validation period (1990-2012).

IMF3, IMF4 and RES for each year, we calculated the simulated value of AR for each year.

For calibration and validation purposes, we divided the whole data series into two periods: the calibration period, i.e., 1960-1989, and the validation period, i.e., 1990-2012. The calibration period is used for parameter estimation for the EEMD, BPANN and nonlinear regression equation. The validation period is used for validating the effectiveness of the hybrid model. The simulation results show the excellent performances of the model for both the calibration (19601989) and validation (1990-2012) periods with $R^{2}$ and AIC value (Fig. 12), which is highly acceptable. Figure 12 shows the observed data of AR and its simulated values by the hybrid model.

In order to compare and validate the simulated results from the hybrid model, we also simulated the AR series by using a single BPANN. Table 3 shows the simulated effect comparisons between the hybrid model and the single BPANN. It can be seen that the coefficient of determination $\left(R^{2}\right)$ of the hybrid model is as high as 0.9747 , whereas that of the single BPANN is only 0.4037. Moreover, the AIC value of the hybrid model (3.1820) is far smaller than that of the single BPANN (171.7801). It is clear that both $R^{2}$ and AIC value indicate that the simulated effect of the hybrid model is much better than that of the single BPANN. Furthermore, the av- 
Table 3. Comparison of simulated effect between the hybrid model and the single BPANN.

\begin{tabular}{lrr}
\hline & $\begin{array}{r}\text { Hybrid } \\
\text { model }\end{array}$ & $\begin{array}{r}\text { Single } \\
\text { BPANN }\end{array}$ \\
\hline$R^{2}$ & 0.9747 & 0.4037 \\
AIC & 3.1820 & 171.7801 \\
Average absolute error $\left(10^{8} \mathrm{~m}^{3}\right)$ & 0.9970 & 3.5477 \\
Average relative error $(\%)$ & 2.9107 & 10.1079 \\
\hline
\end{tabular}

erage absolute and relative error show the high simulation accuracy of the the hybrid model.

All the indices illustrate that the hybrid model is much better than the single BPANN. The reason is that the hybrid model concentrated on the advantages of both EEMD and BPANN, where the EEMD precisely decomposed the nonlinear and nonstationary signal of AR into IMFs, and the BPANN well recognized and accurately simulated the IMFs. Because the nonlinear and nonstationary AR signal contains many components and each component has its own intrinsic mode, a single BPANN can not accurately recognize and simulate all change patterns in AR series. For this reason, this study used an integrated approach to conduct the hybrid model. In order to identify the pattern of each component in the nonlinear and nonstationary AR signal, we firstly used the EEMD to decompose the AR series into four intrinsic mode functions (i.e., IMF1, IMF2, IMF3 and IMF4) and a trend (RES). Then we used the BPANN to accurately recognize the pattern of each IMF by net learning and training, while using the nonlinear regression to exactly simulate the pattern of the trend (RES). The above-simulated results have already proved that our hybrid model is effective.

\section{Conclusions}

Integrating the ensemble empirical mode decomposition, the back-propagation artificial neural network and the nonlinear regression equation, we conducted a hybrid model to simulate the annual runoff of the Kaidu River in northwest China. The main conclusions of this study are as follows:

1. The comparison between simulated values of annual runoff and its original data shows the high simulation accuracy of the hybrid model. Both of the small average absolute and relative errors illustrate the high simulation accuracy of the hybrid model. The big $R^{2}$ and small AIC both indicate that the simulated effect of the hybrid model is much better than that of the single backpropagation artificial neural network.

2. This study elicited an integrated approach to simulate annul runoff of inland rivers, and the framework of the hybrid model conducted by this study can be applied to other inland rivers in northwest China.
Acknowledgements. This work is supported by the Open Foundation (no. G2014-02-07) of the State Key Laboratory of Desert and Oasis Ecology, Xinjiang Institute of Ecology and Geography, Chinese Academy of Sciences.

Edited by: D. Yang

\section{References}

Anderson, D. R., Burnham, K. P., and Thompson, W. L.: Null hypothesis testing: problems, prevalence, and an alternative, J. Wildlife Manage., 64, 912-923, 2000.

Bai, L., Chen, Z. S., Xu, J. H., and Li, W. H.: Multi-scale response of runoff to climate fluctuation in the headwater region of Kaidu River in Xinjiang of China, Theor. Appl. Climatol., doi:10.1007/s00704-015-1539-2, in press, 2015.

Burnham, K. P. and Anderson, D. R.: Model Selection and Multimodel Inference: a practical information-theoretic approach, 2nd Edn., Springer-Verlag, New York, 49-97, 2002.

Chen, Y. N., Xu, C. C., Hao, X. M., Li, W. H., Chen, Y. P., Zhu, C. G., and Ye, Z. X.: Fifty-year climate change and its effect on annual runoff in the Tarim River Basin, China, Quatern. Int., 208, 53-61, 2009.

Chen, Z. S., Chen, Y. N., and Li, B. F.: Quantifying the effects of climate variability and human activities on runoff for Kaidu River Basin in arid region of northwest China, Theor. Appl. Climatol., 111, 537-545, 2013.

Gan, R. and Luo, Y.: Using the nonlinear aquifer storage-discharge relationship to simulate the base flow of glacier-and snowmeltdominated basins in northwest China, Hydrol. Earth Syst. Sci., 17, 3577-3586, doi:10.5194/hess-17-3577-2013, 2013.

Gassman, P. W., Reyes, M. R., Green, C. H., and Arnold, J. G.: The soil and water assessment tool: historical development, applications, and future research directions, T. ASABE, 50, 1211-1250, 2007.

Gusev, E. M., Nasonova, O. N., Dzhogan, L. Y., and Kovalev, E. E.: Northern Dvina runoff simulation using land-surface model SWAP and global databases, Water Resour., 38, 470-483, 2011.

Gusev, Y. M. and Nasonova, O. N.: Modelling heat and water exchange in the boreal spruce forest by the land-surface model SWAP, J. Hydrol., 280, 162-191, 2003.

Hsu, K., Gupta, H. V., and Sorooshian, S.: Artificial neural network modeling of the rainfall-runoff process, Water Resour. Res., 31, 2517-2530, 1995.

Hu, C., Hao, Y., Yeh, T. C. J., Pang, B., and Wu, Z.: Simulation of spring flows from a karst aquifer with an artificial neural network, Hydrol. Process., 22, 596-604, 2008.

Huang, N. E. and Shen, S. S. P.: Transform and Its Applications, World Scientific Publishing Company, Singapore, 1-324, 2005.

Huang, N. E., Shen, Z., Long, S. R., Wu, M. C., Shih, H. H., Zheng, Q., N.-C., Yen, Tung, C. C., and Liu, H. H.: The empirical mode decomposition and the Hilbert spectrum for nonlinear and nonstationary time series analysis, P. Roy. Soc. Lond. A, 454, 903995, 1998.

Huang, N. E., Shen, Z., and Long, S. R.: A new view of nonlinear water waves: the Hilbert Spectrum, Annu. Rev. Fluid Mech., 31, 417-457, 1999. 
Kermani, B. G., Schiffman, S. S., and Nagle, H. G.: Performance of the Levenberg-Marquardt neural network training method in electronic nose applications, Sensor. Actuat. B, 110, 13-22, 2005.

Kroes, J. G., Wesseling, J. G., and Van Dam, J. C.: Integrated modelling of the soil-water-atmosphere-plant system using the model SWAP 2.0 an overview of theory and an application, Hydrol. Process., 14, 1993-2002, 2000.

Labat, D., Ababou, R., and Mangin, A.: Rainfall-runoff relations for karstic springs. Part I: convolution and spectral analyses, J. Hydrol., 238, 123-148, 2000a.

Labat, D., Ababou, R., and Mangin, A.: Rainfall-runoff relations for karstic springs. Part II: continuous wavelet and discrete orthogonal multiresolution analyses, J. Hydrol., 238, 149-178, $2000 \mathrm{~b}$.

Lancaster, P. and Šalkauskas, K.: Curve and Surface Fitting: An Introduction, Academic Press, London, 1-292, 1986.

Lane, S. N.: Assessment of rainfall-runoff models based upon wavelet analysis, Hydrol. Process., 21, 586-607, 2007.

Levesque, E., Anctil, F., Van Griensven, A. N. N., and Beauchamp, N.: Evaluation of streamflow simulation by SWAT model for two small watersheds under snowmelt and rainfall, Hydrolog. Sci. J., 53, 961-976, 2008.

Li, Z. L., Xu, Z. X., Li, J. Y., and Li, Z. J.: Shift trend and step changes for runoff time series in the Shiyang River basin, northwest China, Hydrol. Process., 22, 4639-4646, 2008.

Lin, B., Chen, X., Yao, H., Chen, Y., Liu, M., Gao, L., and James, A.: Analyses of landuse change impacts on catchment runoff using different time indicators based on SWAT model, Ecol. Indic., 58, 55-63, 2015.

Liu, Y. B., Yang, W., and Wang, X.: Development of a SWAT extension module to simulate riparian wetland hydrologic processes at a watershed scale, Hydrol. Process., 22, 2901-2915, 2008.

Liu, Y. B., Yang, W., Yu, Z., Lung, I., Yarotski, J., Elliott, J., and Tiessen, K.: Assessing Effects of Small Dams on Stream Flow and Water Quality in an Agricultural Watershed, J. Hydrol. Eng., 19, 05014015, doi:10.1061/(ASCE)HE.19435584.0001005, 2014.

Luo, Y., Arnold, J., Allen, P., and Chen, X.: Baseflow simulation using SWAT model in an inland river basin in Tianshan Mountains, Northwest China, Hydrol. Earth Syst. Sci., 16, 1259-1267, doi:10.5194/hess-16-1259-2012, 2012.

Ma, Y., Feng, S., Huo, Z., and Song, X.: Application of the SWAP model to simulate the field water cycle under deficit irrigation in Beijing, China, Math. Comput. Model., 54, 1044-1052, 2011.

Maier, H. R. and Dandy, G. C.: The effect of internal parameters and geometry on the performance of back-propagation neural networks: an empirical study, Environ. Modell. Softw., 13, 193209, 1998.

Modarres, R.: Multi-criteria validation of artificial neural network rainfall-runoff modeling, Hydrol. Earth Syst. Sci., 13, 411-421, doi:10.5194/hess-13-411-2009, 2009.

Moghadassi, A. R., Parvizian, F., Hosseini, S. M., and Fazlali, A. R.: A new approach for estimation of PVT properties of pure gases based on artificial neural network model, Braz. J. Chem. Eng., 26, 199-206, 2009.

Moglen, G. E. and Beighley, R. E.: Spatially explicit hydrologic modeling of land use change, J. Am. Water Resour. Assoc., 38, 241-253, 2002.
Nasonova, O. N. and Gusev Y. M.: Can a land surface model simulate runoff with the same accuracy as a hydrological model?. Quantification and reduction of predictive uncertainty for sustainable water resources management, in: Proceedings of Symposium HS2004 at IUGG2007, Perugia, July 2007, IAHS Press, Wallingford, 258-265, 2007.

Nourani, V., Komasi, M., and Mano, A.: A multivariate ANNwavelet approach for rainfall-runoff modeling, Water Resour. Manage., 23, 2877-2894, 2009.

Refsgaard, J. C.: Terminology, modelling protocol and classification of hydrologic model codes, in: Distributed Hydrologic Modelling, edited by: Abbott, M. B. and Refsgaard, J. C., Kluwer Academic Publishers, Dordrecht, 41-54, 1996.

Sahay, R. R. and Srivastava, A.: Predicting monsoon floods in rivers embedding wavelet transform, genetic algorithm and neural network, Water Resour. Manage., 28, 301-317, 2014.

Sang, Y. F.: A practical guide to discrete wavelet decomposition of hydrologic time series, Water Resour. Manage., 26, 3345-3365, 2012.

Seibert, J.: Multi-criteria calibration of a conceptual runoff model using a genetic algorithm, Hydrol. Earth Syst. Sci., 4, 215-224, doi:10.5194/hess-4-215-2000, 2000.

Shao, Q., Wong, H., Li, M., and Ip, W. C.: Streamflow forecasting using functional-coefficient time series model with periodic variation, J. Hydrol., 368, 88-95, 2009.

Shope, C. L., Maharjan, G. R., Tenhunen, J., Seo, B., Kim, K., Riley, J., Arnhold, S., Koellner, T., Ok, Y. S., Peiffer, S., Kim, B., Park, J.-H., and Huwe, B.: Using the SWAT model to improve process descriptions and define hydrologic partitioning in South Korea, Hydrol. Earth Syst. Sci., 18, 539-557, doi:10.5194/hess-18-5392014, 2014.

Su, M. F. and Wang, H. J.: Relationship and its instability of ENSO Chinese variations in droughts and wet spells, Sci. China Ser. D, 50, 145-152, 2007.

Tokar, A. S. and Johnson, P. A.: Rainfall-runoff modeling using artificial neural networks, J. Hydrol. Eng., 4, 232-239, 1999.

Trivedi, H. V. and Singh, J. K.: Application of grey system theory in the development of a runoff prediction model, Biosyst. Eng., 92, 521-526, 2005.

van Dam, J. C., Huygen, J., Wesseling, J. G., Feddes, R. A., Kabat, P., van Walsum, P. E. V., Groenendijk, P., and van Diepen, C. A.: Theory of SWAP version 2.0: simulation of water flow, solute transport and plant growth in the Soil-Water-AtmospherePlant environment, Technical Document 45, DLO Winand Staring Centre, Report 71, Department Water Resources, Wageningen Agriculture University, Wageningen, 1-176, 1997.

Wang, J., Li, H., and Hao, X.: Responses of snowmelt runoff to climatic change in an inland river basin, Northwestern China, over the past 50 years, Hydrol. Earth Syst. Sci., 14, 1979-1987, doi:10.5194/hess-14-1979-2010, 2010.

Wu, Z. H. and Huang, N. E.: A study of the characteristics of white noise using the empirical mode decomposition method, P. Roy. Soc. Lond. A, 460, 1597-1611, 2004.

Wu, Z. H. and Huang, N. E.: Ensemble empirical mode decomposition: A noise-assisted data analysis method, Adv. Adapt. Data Anal., 01, 1-41, 2009.

Wu, Z. H., Huang, N. E., Long, S. R., and Peng, C. K.: On the trend, detrending, and variability of nonlinear and nonstationary time series, P. Natl. Acad. Sci. USA, 104, 14889-14894, 2007. 
Wu, Z. H., Huang, N. E., Wallace, J. M., Smoliak, B. V., and Chen, $\mathrm{X}$. Y.: On the time-varying trend in global-mean surface temperature, Clim. Dynam., 37, 759-773, 2011.

$\mathrm{Xu}$, J. H.: Mathematical methods in contemporary geography, Higher Education Press, Beijing, 37-105, 2002.

Xu, J. H., Chen, Y. N., Li, W. H., Ji, M. H., and Dong, S.: The complex nonlinear systems with fractal as well as chaotic dynamics of annual runoff processes in the three headwaters of the Tarim Rive, J. Geogr. Sci., 19, 25-35, 2009.

Xu, J. H., Li, W. H., Ji, M. H., Lu, F., and Dong, S.: A comprehensive approach to characterization of the nonlinearity of runoff in the headwaters of the Tarim River, western China, Hydrol. Process., 24, 136-146, 2010.

Xu, J. H., Chen, Y. N., Li, W. H., Yang, Y., and Hong, Y. L.: An integrated statistical approach to identify the nonlinear trend of runoff in the Hotan River and its relation with climatic factors, Stoch. Environ. Res. Risk A., 25, 223-233, 2011.

Xu, J. H., Chen, Y. N., Li, W. H., Nie, Q., Song, C. N., and Wei, C. M.: Integrating wavelet analysis and BPANN to simulate the annual runoff with regional climate change: a case study of Yarkand River, Northwest China, Water Resour. Manage., 28, 2523-2537, 2014.
Xue, C. F., Hou, W., Zhao, J. H., and Wang, S. G.: The application of ensemble empirical mode decompositon method in multiscale analysis of region percipitation and its response to the climate change, Acta Phys. Sin., 62, 10923, doi:10.7498/aps.62.109203, 2013.

Yang, D. W. and Musiake, K.: A continental scale hydrological model using the distributed approach and its application to Asia, Hydrol. Process., 17, 2855-2869, 2003.

Yang, D. W., Gao, B., Jiao, Y., Lei, H. M., Zhang, Y. L., Yang, H. B., and Cong, Z. T.: A distributed scheme developed for ecohydrological modeling in the upper Heihe River, Sci. ChinaEarth Sci., 58, 36-45, 2015.

Yarar, A.: A hybrid wavelet and neuro-fuzzy model for forecasting the monthly streamflow data, Water Resour. Manage., 28, 553$565,2014$.

Yu, P. S., Chen, C. J., Chen, S. J., and Lin, S. C.: Application of grey model toward runoff forecasting, J. Am. Water Resour. Assoc. 37, 151-166, 2001.

Zhao, Q., Liu, Z., Ye, B., Qin, Y., Wei, Z., and Fang, S.: A snowmelt runoff forecasting model coupling WRF and DHSVM, Hydrol. Earth Syst. Sci., 13, 1897-1906, doi:10.5194/hess-131897-2009, 2009. 